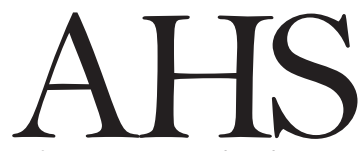

Advances in Horticultural Science

\section{Warm stratification improves embryos development and seed germination of Cycas revoluta}

\author{
J. Benjelloun, S. Bouzroud (*), Z.E. Triqui, Q. Lahlimi Alami, R. Layachi, A. \\ Smouni, A. Guedira \\ Laboratoire de Biotechnologie et Physiologie Végétales, Centre de \\ Biotechnologie Végétale et Microbienne Biodiversité et Environnement, \\ Faculté des Sciences, Université Mohammed V de Rabat, Morocco.
}

Key words: Cycas revoluta, development, germination, treatment, warm stratification, zygotic embryos.

\begin{abstract}
The broad objective of this research is to study the effect of warm stratification on Cycas revoluta zygotic embryos length, seed germination and plant development. Four warm treatments were applied to seeds. Our results showed that seeds storage at room temperature or $30^{\circ} \mathrm{C}$ improved significantly zygotic embryos length. Moreover, time of germination was significantly reduced with the warm stratification. The highest percentage of germination was obtained with seeds warm treated at $30^{\circ} \mathrm{C}$ for 2 months while only $25 \%$ of seeds were able to germinate in the control. Regarding seedlings development, our results demonstrated that warm stratification did not affect plant development. No significant differences have been recorded in all the evaluated parameters except for root length. Taken together, these results underlined the beneficial effect of warm stratification on Cycas revoluta seed germination and plant development and proposed a new method to improve seed germination of Cycas revoluta.
\end{abstract}

\section{Introduction}

The sago palm (Cycas revoluta L.) is one of the widespread ornamental trees, grown in temperate, subtropical and tropical regions more precisely in Miyazaki and Kagoshima Prefectures in Kyushu District down to the Ryukyu Islands, Okinawa Prefecture in Japan (Zarchini et al., 2011). Described as one of the most primitive species among the living cycads, Cycas revoluta has been used as an indoor and outdoor landscape plant for centuries (Stevenson, 1990; Jones, 1994).

Cycas revoluta is propagated either from seeds, which remain viable for only a short time, or from vegetative offshoots (Demiray et al., 2017). Germination of seed of Cycas revoluta is hard and time consuming (Zarchini et al., 2011). Seeds can take 3 to 9 months to initiate germination before they can continue to germinate for periods of a year or more. C. revoluta seeds also demonstrates rapid loss of viability and low mor- 
phogenic potential, which hinder its conservation (NADERI et al., 2015).

Breaking dormancy is the main problem faced by all Cycas revoluta (Frett, 1987). Several attempts have been made to overcome with Cycas revoluta seed dormancy problem. Priming treatments of seeds seems to offer a new way to increase seeds germination percentage. Mechanical and chemical scarification has been described widely as an efficient way to improve germination of the hard-seeds species of Cycas and some other species known for their hard-coated seeds (Frett, 1987; Rouhi et al., 2010). Indeed, several studies have reported a great responsiveness of Cycads seeds to various pretreatments, namely, scarification, depulping, exposure to chemical substances like potassium nitrate, gibberellic acid or sulfuric acid or soaking in hot water for specific period of time (Zarchini et al., 2011; Millaku et al., 2012). Warm stratification was also used to improve seed germination of many species such as Sambucus and Symphoricarpos (Baskin et al., 2002). The present study aimed to improve the germination of Cycas revoluta seeds through different warm stratification treatments as a way to develop an efficient in vivo germination protocol for this ornamental species.

\section{Materials and Methods}

\section{Plant material}

Freshly harvested seeds collected from 50 years old female mature plants grown in Faculty of Sciences garden, University Mohammed $\mathrm{V}$ in Rabat (Morocco) were used in this study.

\section{Zygotic embryos length measurement}

Seeds were soaked in water for 48 hours in order to soften the sacrotesta; the orange external layer. The sacrotesta was then removed mechanically with a knife. Seeds were then flamed with ethanol for 2 minutes. Sclerotesta layer was mechanically eliminated. The megagametophytes were surface sterilized for 20 minutes by soaking in $30 \%$ dilution of $\mathrm{NaOCl}$ containing 2-3 drops of Tween-20, followed by 3-4 rinses with sterile distilled water. After surface sterilization, megagametophytes were pooled, longitudinally bisected and the zygotic embryo (ZE) was excised from each megagametophyte. ZEs length was measured and the mean was calculated from at least 20 biological replicates.
Warm stratification treatments and seeds cultivation

After removing the sacrotesta mechanically, equal samples of seeds were subjected to different treatments. Treatments consisted in seed storage at room temperature $\left(18-20^{\circ} \mathrm{C}\right)$ or $30^{\circ} \mathrm{C}$ for 2 or 4 months depending on the treatment (Table 1). The warm stratification temperatures were chosen based on previous reports that underlined the beneficial effect of seed storage at $18^{\circ} \mathrm{C}$ and $30^{\circ} \mathrm{C}$ on seed's germination (Roh et al., 2004; Baldos et al., 2014; Keun et al., 2016). Untreated seeds were cultivated immediately and referred as control treatment $\left(\mathrm{T}_{0}\right)$. Seeds of Cycas revoluta were then planted in bins containing sterilized soil at $2-5 \mathrm{~cm}$ depth. Cultures were incubated at $25 \pm 2^{\circ} \mathrm{C}$, with a photoperiod of 16 hours of light and 8 hours of darkness and watered daily depending on soil moisture.

Table 1 - Different heat treatments used to enhance seed germination of Cycas revoluta

\begin{tabular}{lcc}
\hline Treatment & $\begin{array}{c}\text { Type of } \\
\text { treatment }\end{array}$ & $\begin{array}{c}\text { Time of } \\
\text { application }\end{array}$ \\
\hline $\mathrm{T}_{0}$ & $\begin{array}{c}\text { Control/Untreated } \\
\mathrm{T}_{1}\end{array}$ & $\begin{array}{c}\text { hours } \\
\mathrm{T}_{2}\end{array}$ \\
$\mathrm{~T}_{3}$ & Room temperature $\left(18-20^{\circ} \mathrm{C}\right)$ & 2 months \\
$\mathrm{T}_{4}$ & $30^{\circ} \mathrm{C}$ & 2 months \\
\hline
\end{tabular}

\section{Germination and plant growth parameters recording}

Weekly observations were performed and seed emergence was recorded after 10 months of cultivation. The data for the kinetic of germination and time of germination (days) were recorded. Percentage of germination was calculated after ten months of culture. Number of leaves, stip height and width, root length and the length of the most developed leaf were determined at the end of the experiment.

\section{Statistical analysis}

Zygotic embryos length, time of germination, number of leaves, stip height and width, root length and the length of the most developed leaf were compared using a fixed model of analysis of variance (ANOVA). For each parameter and condition, means were calculated based on at least thirty biological replicates. In case of significant difference between groups, a Tukey test was used for means separation, at risk of 0.05 . 


\section{Results}

Effect of warm stratification on zygotic embryos length

Zygotic embryos (ZEs) length was investigated in the different warm pre-treatments. Our results showed that all the applied treatments $\left(T_{1}, T_{2}, T_{3}\right.$ and $T_{4}$ ) influenced ZEs length compared with the untreated seeds $\left(T_{0}\right)$ (Fig. 1). ZEs length of seeds subjected to $T_{1}, T_{2}, T_{3}$ and $T_{4}$ was significantly enhanced, but no significant difference was observed between $T_{3}$ and $\mathrm{T}_{4}$ seeds. Indeed, ZEs length increased by $134 \%$, $276 \%, 300 \%$ and $342 \%$ in $\mathrm{T}_{1}, \mathrm{~T}_{2}, \mathrm{~T}_{3}$ and $\mathrm{T}_{4}$ warm treated seeds respectively when compared to untreated seeds.

\section{Effect of warm stratification on seed's germination}

As mean to gain more insight on the effect of warm storage on seed germination, time of germination (calculated starting from the first day of seeds cultivation), percentage of germination and its kinetic were determined for each treatment. The results were summarized in figures 2,3 and 4 .

\section{A}

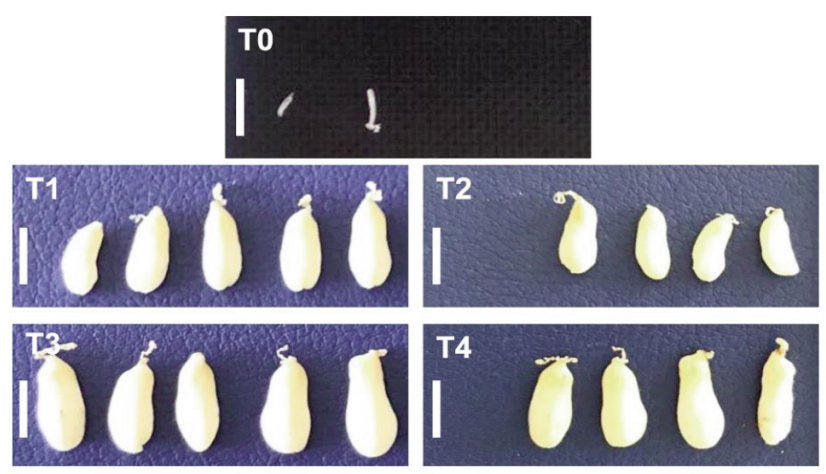

B

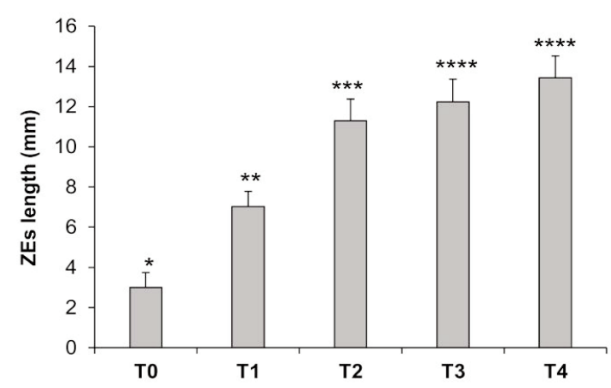

Fig. 1 - Effect of warm stratification treatments on Cycas revoluta embryos length. (A) Zygotic embryos isolated from seeds subjected to T0, T1, T2, T3 and T4. Scale bars=1 $\mathrm{cm}$. (B) Zygotic embryos length in the different treatments. Bars are mean \pm SD of at least thirty biological replicates. Asterisks indicate statistical difference according to Tukey test $(p<0.05)$.
Effect of warm stratification on the time of germination

Minimum time of germination (163.33 days) was recorded in seeds stored at $30^{\circ} \mathrm{C}$ for 4 months followed by those stored at $30^{\circ} \mathrm{C}$ for 2 months (198.19 days) and those stored at room temperature for 4 months (202 days). Note that the difference between these three treatments was statistically insignificant. Untreated seeds $\left(T_{0}\right)$ and those stored at room temperature for 2 months $\left(T_{1}\right)$ took the maximum time duration for germination with an average of 294.4 days and 256.75 days respectively (Fig. 2).

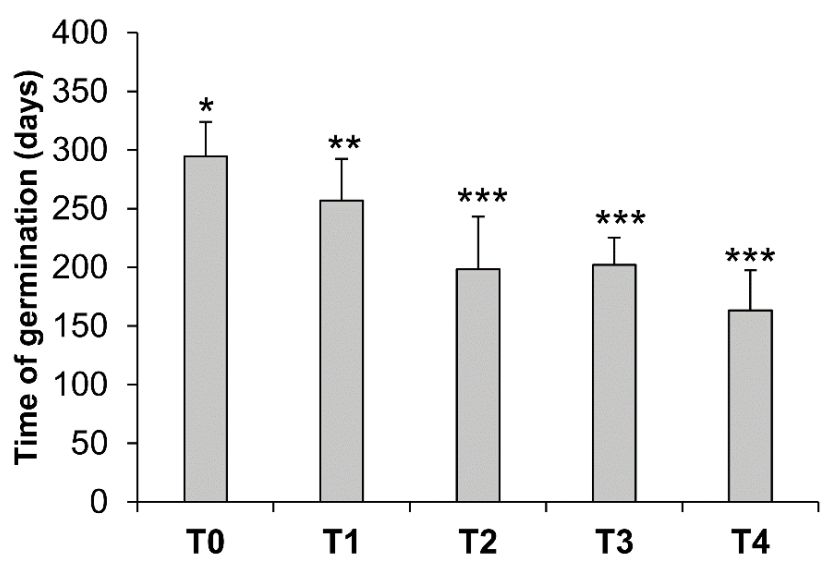

Fig. 2 - Effect of different warm stratification treatments on the time of germination of Cycas revoluta embryos Bars are mean \pm SD of at least thirty biological replicates. Asterisks indicate statistical difference according to Tukey test $(p<0.05)$.

Effect of warm stratification on the percentage of germination

Investigating the percentage of germination of seeds from the four different treatments and the untreated ones revealed that seed germination response varied among the different warm treatments. The highest percentage of germination (49.33\%) was recorded in seeds stored for 2 months at $30^{\circ} \mathrm{C}$ while the lowest value of $8 \%$ was observed for seeds stored at room temperature for 4 months (Fig. 3). Untreated seeds showed although a percentage of germination around $25 \%$.

Effect of warm stratification on the kinetic of germination

Investigating the kinetic of germination revealed a high variability between the different treatments applied (Fig. 4). Our data showed that seeds storage at $30^{\circ} \mathrm{C}$ for two or four months $\left(T_{2}\right)$ allowed seeds to germinate faster. Indeed, seeds started to germinate 
after four months of culture whereas, the first germinated seeds appeared after five months and 6 months respectively for $T_{1}$ and $T_{0}$. Seeds storage at room temperature for four months $\left(T_{3}\right)$ delayed the germination by one month compared to untreated

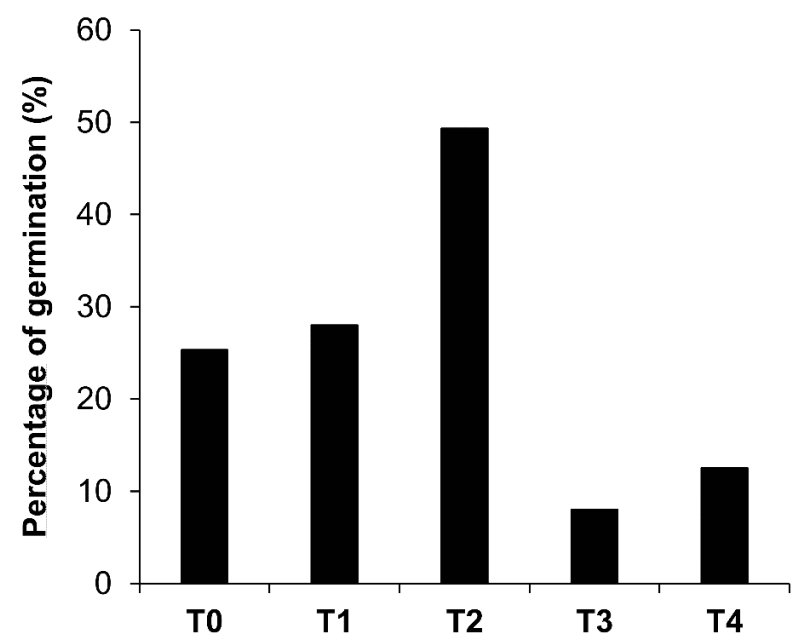

Fig. 3 - Effect of different warm stratification treatments on the percentage of germination of Cycas revoluta embryos.

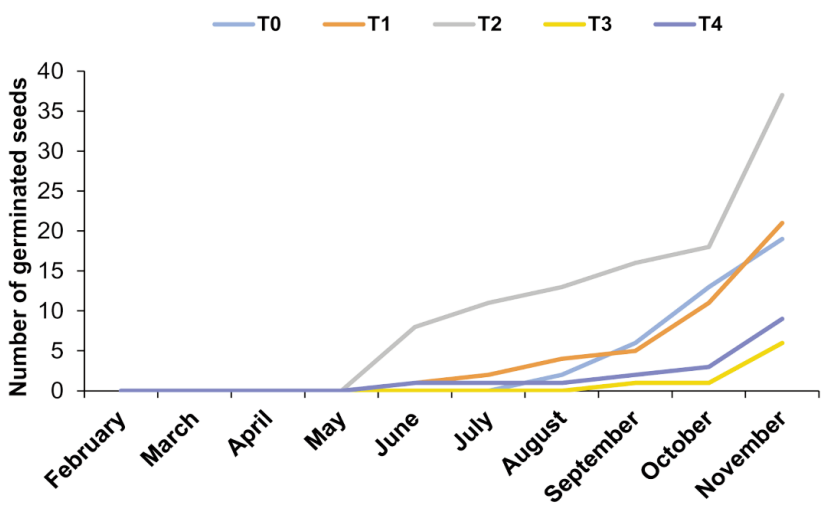

Fig. 4 - Effect of different warm stratification treatments on the kinetic of germination of Cycas revoluta embryos. seeds $\left(T_{0}\right)$. These data joined those related to time of germination.

\section{Effect of warm stratification on plant's growth and} development

Seeds pre-treatment with temperature affected zygotic embryos length and their germination. These results prompted us to see whether the pre-treatment can influence seedlings growth and development. Several growth parameters namely, number of leaves per plant, stip height and width, root length and the length of the most developed leaf were evaluated. Table 2 summarized the results.

Data analysis had shown that seeds pre-treatment did not affect the number of leaves per plant. Seeds storage for 2 months at $30^{\circ} \mathrm{C}$ gave a maximum number of leaves per plant $(1.50 \pm 0.59)$ while the lowest value was obtained with $\mathrm{T}_{4}$ treatment $(1.14 \pm 0.37)$. Note that these differences remained insignificant. Leaf length was also not significantly affected by the priming treatments. It was found that maximum leaf length was $57.33 \pm 3.05 \mathrm{~cm}$ in seedlings subjected to $\mathrm{T}_{3}$ treatment while a minimum of $48.22 \pm 4.23 \mathrm{~cm}$ was recorded with $\mathrm{T}_{1}$ treatment.

Stip height showed no significant difference between the different treatments. Stip width, on the other hand, displayed significant variations between the different treatments. A significant increase in stip width was observed in seedlings subjected to $T_{1}$ and $\mathrm{T}_{2}$ as compared to the control $\left(\mathrm{T}_{0}\right)$ while non-significant changes was observed between the remaining treatments $\left(\mathrm{T}_{3}\right.$ and $\left.\mathrm{T}_{4}\right)$.

Regarding root development, root length showed significant variations between the different treatments. Seeds storage for 2 months at $30^{\circ} \mathrm{C}$ resulted in a significant increase in root length compared to untreated seeds while a decrease in root length was observed with $\mathrm{T}_{3}$ and $\mathrm{T}_{4}$ treatments.

Table 2 - Effect of different priming treatments on growth parameters of Cycas revoluta seedlings

\begin{tabular}{lccccc}
\hline Treatments & $\begin{array}{c}\text { Number of } \\
\text { leaves/plant }\end{array}$ & $\begin{array}{c}\text { Stip height } \\
(\mathrm{cm})\end{array}$ & $\begin{array}{c}\text { Stip width } \\
(\mathrm{cm})\end{array}$ & $\begin{array}{c}\text { Leaf length } \\
(\mathrm{cm})\end{array}$ & $\begin{array}{c}\text { Root length } \\
(\mathrm{cm})\end{array}$ \\
\hline $\mathrm{T}_{0}$ & $1.31 \pm 0.47 \mathrm{a}$ & $3 \pm 0.47 \mathrm{a}$ & $1.81 \pm 0.19 \mathrm{~b}$ & $50.63 \pm 6.24 \mathrm{abc}$ & $26.62 \pm 3.15 \mathrm{bc}$ \\
$\mathrm{T}_{1}$ & $1.20 \pm 0.42 \mathrm{a}$ & $3.92 \pm 0.32 \mathrm{a}$ & $2.10 \pm 0.24 \mathrm{a}$ & $48.22 \pm 4.23 \mathrm{bc}$ & $21.60 \pm 2.07 \mathrm{~cd}$ \\
$\mathrm{~T}_{2}$ & $1.50 \pm 0.59 \mathrm{a}$ & $3.77 \pm 0.45 \mathrm{a}$ & $2.15 \pm 0.22 \mathrm{a}$ & $55.91 \pm 4.25 \mathrm{ab}$ & $35.42 \pm 2.69 \mathrm{a}$ \\
$\mathrm{T}_{3}$ & $1.33 \pm 0.57 \mathrm{a}$ & $3.5 \pm 0.86 \mathrm{a}$ & $1.86 \pm 0.30 \mathrm{ab}$ & $57.33 \pm 3.05 \mathrm{a}$ & $31.66 \pm 2.31 \mathrm{ab}$ \\
$\mathrm{T}_{4}$ & $1.14 \pm 0.37 \mathrm{a}$ & $3.50 \pm 0.47 \mathrm{a}$ & $1.58 \pm 0.15 \mathrm{~b}$ & $49 \pm 5 \mathrm{c}$ & $21 \pm 3 \mathrm{~d}$ \\
\hline
\end{tabular}

Values are mean \pm SD of at least thirty biological replicates. Values with different letters indicate the statistical significance $(p<0.05)$ according to Tukey test. 


\section{Discussion and Conclusions}

Cycas revoluta is an ornamental tree that has been widely used as an indoor and outdoor landscape. However, despite its importance in landscape design, it is facing problems regarding its germination mainly due to the hard-coat (Ullah et al., 2020). Different methods have been tested to overcome hardseededness. These include mechanical, chemical, and physical scarification treatments to make the seed coat permeable for water uptake. Several reports have shown that seeds pre-treatment with sulphuric acid $\left(\mathrm{H}_{2} \mathrm{SO}_{4}\right)$, potassium nitrate $\left(\mathrm{KNO}_{3}\right)$ or $\mathrm{GA}_{3}$ results in a better germination results. Indeed, Zamia furfuracea and Cycas revoluta germinations were assessed by Schutzman, using a chemical scarification with concentrated $\mathrm{H}_{2} \mathrm{SO}_{4}$ and then soaking them in gibberellic acid ( $\mathrm{GA}_{3}$ ) (Schutzman, 1984, 1989). However, these pretreatments are not always reliable with cycads (Dehgan and Yuen, 1983). For instance, Zarchini et al. (2011) have found that the use of sulphuric acid even at lower concentrations seems to affect negatively seed's germination while combined with hot water seems to improve Cycas revoluta seed germination.

It is well admitted that seeds storage in a warm environment usually results in relatively rapid embryos development (Baskin et al., 2002; Merritt et al., 2007; Razavi and Hajiboland, 2009). However, no previous work has been conducted to study the effect of seed storage in warm conditions on Cycas revoluta germination and seedlings development. Thus, we investigated the effect of warm storage on zygotic embryos development, seeds germination and growth of young seedlings of Cycas revoluta. Our results showed that warm storage at $30^{\circ} \mathrm{C}$ for 2 months or 4 months speeded the germination when compared to the untreated plot (Fig. 2). Seeds storage at $30^{\circ} \mathrm{C}$ for 2 months improves also the germination percentage. Meanwhile, the prolonged storage at $30^{\circ} \mathrm{C}$ for 4 months reduced the germination percentage by half compared to the untreated plot which suggest that prolonged storage have an inhibitive effect rather than stimulating the germination (Fig. 3). Chen et al. (2007) have found that Prunus campanulata seeds required 4-6 weeks of warm followed by 8 weeks of cold stratification for maximum germination percentage. This finding was explained by the accumulation of high amounts of GA as a result of the cold stratification while GAs in warm stratified embryos were significantly low. Thus,
Prunus warm stratified embryos failed to germinate since GAs content was very low. In $\mathrm{H}$. salicornicum and $S$. imbricate, seeds germination was significantly improved when seeds were stored at $40 \pm 2^{\circ} \mathrm{C}$ for three months (El-Keblawy, 2013). Warm stratification for at least 1 month appeared to be essential for the germination of Japanese snowbell (Styrax japonicus) (Baskin, 2009). Indeed, Roh and Bentz (2003) found that without warm stratification, seeds were not able to germinate. Seed's dormancy in some orchids, mainly Epipactis palustris and Goodyera pubescens, could be overcame by a warm incubation of seeds followed by cold storage. This was explained by the fact that warm and cold stratification increased seeds permeability to water thereby softening the testa (Roh and Bentz, 2003). Thus, the increase observed in germination percentage could be attributed to the increase of seed's hard coat permeability caused by the warm storage which allow the removal of the physical barrier to water absorption. Besides the improvement of seeds germination percentage and the reduction of the germination time, warm storage improved significantly zygotic embryos length which suggest that warm scarification result in a better development of zygotic embryos. Regarding seedlings development, our data showed that warm scarification did not affect plant development (Fig. 5). Indeed, no significant differences have been recorded in all the evaluated parameters except for root length. Taken together, these results suggest that warm scarification improved seeds development and germination by prompting zygotic embryos length, increasing germination percentage and reducing time of germination.

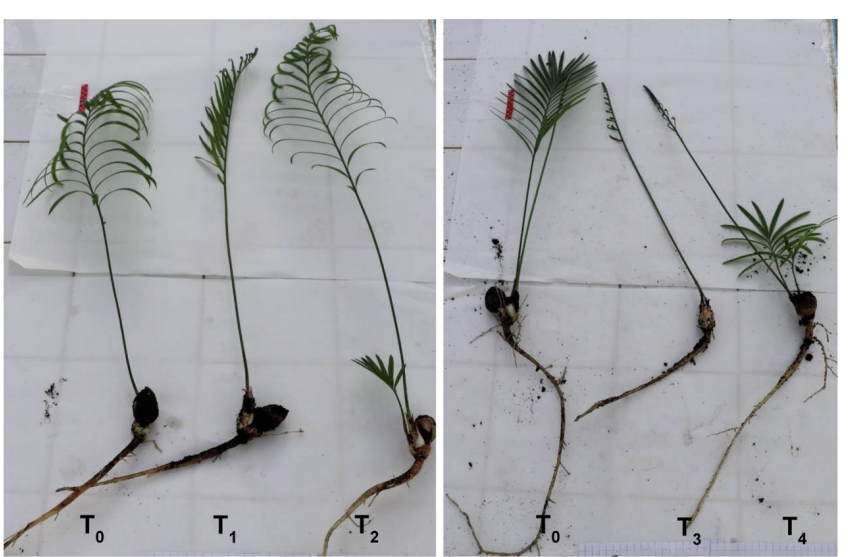

Fig. 5 - Cycas revoluta plants obtained from pre-treated seeds with temperature (T1, T2, T3 and T4) and untreated seeds (TO). 
This study aims to study the effect of seeds storage at different temperatures on Cycas revoluta seeds germination and development in order to develop an efficient in vivo germination protocol that can be used for mass production of this ornamental tree. Based on our results, we found that seeds storage at $30^{\circ} \mathrm{C}$ for 2 months or 4 months reduced time of germination. However, the highest percentage of germination was only assessed when seeds were stored at $30^{\circ} \mathrm{C}$ for 2 months. Taken together, this protocol represents a useful and potential method to improve commercial mass propagation of Cycas revoluta.

\section{References}

BALDOS O.C., DEFRANK J., FRAMER M., SAKAMOTO G.S., 2014 - Storage humidity and temperature affect dormancy loss and viability of tanglehead (Heteropogon contortus) seeds. - HortSci., 49: 1328-1334.

BASKIN C.C., ZACKRISSON O., BASKIN J.M., 2002 - Role of warm stratification in promoting germination of seeds of Empetrum hermaphroditum (Empetraceae), a circumboreal species with a stony endocarp. - Am. J. Bot., 89: 486-493.

BASKIN J.M., 2009 - The woody plant seed manual. - Nativ. Plants J., 10(3): 300-301.

CHEN S.Y., CHIEN C.T., CHUNG J.D., YANGY.S., KUO S.R., 2007 - Dormancy-break and germination in seeds of Prunus campanulata (Rosaceae): role of covering layers and changes in concentration of abscisic acid and gibberellins. - Seed Sci. Res., 17(1): 21-32.

DEHGAN B., YUEN C.K.K.H., 1983 - Seed morphology in relation to dispersal, evolution, and propagation of Cycas L. - Bot. Gaz., 144(3): 412-418.

DEMIRAY H., DEREBOYLU A.E., YAZICI Z.I., BILDIK S., BULBUL K., SENOL S.G., PIRHAN A.F., 2017 - In vitro seed germination of Cycas revoluta thunb. - Bangladesh J. Bot., 46(2): 559-564.

EL-KEBLAWY A., 2013 - Effects of seed storage on germination of two succulent desert halophytes with little dormancy and transient seed bank. - Acta Ecol. Sin., 33(6): 338-343.

FRETT J.J., 1987 - Seed germination of Cycas revoluta. - J. Environ. Hortic., 5: 105-106.
JONES D.L., 1994 - Cycads of the world. - Smithsonian Inst. Press, Washington, DC, USA, pp. 312.

KEUN S.J., HEE K.J., KYUNG L.A., 2016 - Effect of warm and cold stratification, and ethanol treatment on germination of Corylopsis seeds. - Hortic. Sci., 43: 84-91.

MERRITT D.J., TURNER S.R., CLARKE S., DIXON K.W., 2007 Seed dormancy and germination stimulation syndromes for Australian temperate species. - Aust. J. Bot., 55: 336-344.

MILLAKU F., GASHI B., ABDULLAI K., ALIU S., OSMANI M., KRASNIQI E., MATA V., RYSHA A., 2012 - Effects of coldstratification, gibberellic acid and potassium nitrate on seed germination of yellow gentian (Gentiana lutea L.). - African J. Biotechnol., 11: 13173-13178.

NADERI R., MOHAISENI K., DA SILVA J.A.T., OMIDI M., NADERI B., 2015 - Simplified regeneration protocol for Cycas revoluta Thunb. Mature zygotic embryos. - Not. Sci. Biol., 7: 62-65.

RAZAVI S.M., HAJIBOLAND R., 2009 - Dormancy breaking and germination of Prangos ferulaceae seeds. EurAsian J. Biosci., 3: 78-83.

ROH M.S., BENTZ J.A., 2003 - Germination of styrax japonicus seeds as influenced by storage and sowing conditions. - Acta Horticulturae, 620: 411-416.

ROH M.S., BENTZ J.A., WANG P., ERCHENG L.I., KOSHIOKA M., 2004 - Maturity and temperature stratification affect the germination of Styrax japonicus seeds. - J. Hortic. Sci. Biotechnol., 79(4): 645-651.

ROUHI H.R., AFSHARI R.T., SHAKARAMI K., 2010 - Seed treatments to overcome dormancy of waterlily tulip (Tulipa kaufmanniana Regel.). - Aust. J. Crop Sci. 4(9): 718-721.

SCHUTZMAN B., 1984 - A new species of Zamia L. (Zamiaceae, Cycadales) from Chiapas, Mexico. Phytologia, 55: 299-304.

SCHUTZMAN B., 1989 - A new species of Zamia from Honduras. - Syst. Bot., 14(2): 214-219.

STEVENSON D.W., 1990 - Morphology and systematics of the Cycadales. - Mem. New York Bot. Gard., 57: 8-55.

ULLAH Z., HASSAN I., HAFIZ I.A., ABBASI N.A., 2020 - Effect of different priming treatments on seed germination of sago palm (Cycas revoluta L.). - World J. Biol. Biotechnol., 5: 1-3.

ZARCHINI M., HASHEMABADI D., KAVIANI B., FALLAHABADI P.R., NEGAHDAR N., 2011 - Improved germination conditions in Cycas revoluta L. by using sulfuric acid and hot water. - Plant Omics., 4(7): 350-353. 